\title{
Shaping the quality of second language learning: Students' perspective
}

\author{
Irina M. Solodkova ${ }^{l, *}$, Elena $V$. Grigorieva ${ }^{I}$, and Liliya $R$. Ismagilova ${ }^{l}$ \\ ${ }^{1}$ Kazan Federal University, 18, Kremlevskaya St., Kazan, 420012, Russia
}

\begin{abstract}
The paper dwells on the problem of identifying the most crucial factors affecting the quality of foreign language learning from the students' perspective. Quality foreign language education is a disputable issue in 21 century due to the increased global workforce competition. Human capital has a great impact on education as an important factor in shaping a new quality of country's economy and well-being of society. Foreign language skill is an integral component of highly qualified professionals as the global economic processes make them participate in cross-border business communication. In these conditions the aim of higher education establishments is to provide quality of language learning and teaching that allows future specialists not to distort the meaning in written and oral communication within their professional framework. The two-phase survey conducted among 67 students of the Institute of Management, Economics and Finance of the Kazan Federal University provided with quantitative data. The respondents ranked differently the factors determining the quality of language learning and teaching responses after two years of completing their foreign language education and were generally satisfied with the quality of service rendered. The obtained results give optimistic forecasts regarding the improvement of foreign language education and help reconsider the way of teaching a foreign language basing on the chosen factors.
\end{abstract}

Keywords: foreign language, learning, quality foreign language education, communicative competence, facilities and teaching materials, education infrastructure

\section{Introduction}

Intellectual potential is proclaimed to be the main source of welfare in the 21 st century. The potential of human capital could be determined by the extent to which fundamental science is developed, by the overall level of education people of the particular country have, as well as by the accessibility of education to the broad layers of population.

The influential role of human capital has a great impact on education as an important factor in shaping a new quality of country's economy and well-being of society in general. Education is a source of formation of qualified human resources and a key driver in country's competitiveness, its economic growth, its future stability and prosperity $[1,2]$.

*Corresponding author: imsold@mail.ru 
In this regard, the system of higher education is to be modernized, first of all, improving the quality of services rendered. The new quality of education should not be oriented only at assimilation a certain amount of knowledge needed for successful accomplishment of professional duties, but also at the development of future specialists' personality, their cognitive and creative abilities, vital competencies and skills.

In the context of our research we discuss the factors that affect the quality of foreign language education in particular. Authors would like to investigate students' perspective on the discussed issue as they act as the ordering consumers of the educational service. The analysis of students' answers would allow reconsider the way of teaching a foreign language basing on the chosen factors.

Foreign language skill is an integral component of highly qualified professionals as the global economic processes make them participate in cross-border business communication. English for specific purposes is defined as "a complex of linguistic means used by specialists of a certain field of knowledge with the aim to provide an unambiguous understanding" [3]. Following this definition, the aim of higher educational institution is to provide qualitative language proficiency level in their specialty. The one that would allow future specialists to communicate with colleagues worldwide successfully and to become international workforce. That means that the process of teaching a foreign language 'is supposed to be based on effective study strategies and established on the basis of sustainable development, with a high quality result as a final outcome'. High quality teaching is 'to train students to become effective and confident language users, to get involved into problem-solving easily and independently, to become cooperative and excellent workers and integrative thinkers' [4].

\section{Theoretical background}

It is obvious that the issue of quality in ESP teaching and learning is not a recent trend. The changes that occurred in socio-economic and political spheres in different periods influenced the changes in the requirements for language training. Since 1985, one of the distinctive features of public life in Russia has become an increased interest in a foreign language learning. It happened due to an open policy of the country towards the world community. That period is distinguished by an introduction of early learning of a foreign language in secondary schools, by the transfer of the subject to the category of educational disciplines of federal significance, by an increased number of people (including some narrow specialists) involved into foreign language studying. Thus, the ongoing socioeconomic and political processes determine the social requirements of the society to the level and quality of a foreign language. Social order acts as a "strategic benchmark for foreign language teaching policy" [5]. Society requires specialists who are able to communicate with foreigners on topics within their professional framework as well as in everyday informal settings. The same aims are set by the Federal Standard. It indicates the importance of the four language skills (listening, speaking, reading, writing) which have to be acquired to the extent that allows not to distort the meaning in written and oral communication in the professional sphere. So, using English in professional surroundings does not mean using clichés, memorized cues, speech blocks and texts, but the ability to freely combine linguistic units to express their thoughts in any situation.

The English language Syllabus implies the formation of such skills as:

- the ability to use information of a linguistic nature and to master the basics of everyday communication;

- the opportunity to conduct business contacts with foreign partners (including presentations, negotiations, including telephone calls);

- the ability to improve their activities, drawing on the data of foreign sources; 
- the ability to process texts in various types of business documents: reports, letters, memos, orders, etc.

Following these points we may assume that to get high quality of language education there should be strict auditing of target that is to develop learners' communicative competence [6, 7, 8]. W. M. Rivers [7] emphasizes the importance of students' ability to interact freely in order to bridge the gap between what they say and what others share. To reach communicative competence language tasks and activities must make students take part in different communicative practices such as 'exchanging information, negotiation of meaning, and interaction' [9]. Lessons structured on communicative method involve language learners in the 'pragmatic, authentic, functional use of language for meaningful purposes, fluency and accuracy are seen as complementary principles underlying communicative techniques, students ultimately have to use the language, productively and receptively, in unrehearsed contexts' $[9,8]$.

Having defined the aim of language education, it is crucial to detect the factors which help to form and to later maintain and develop high quality of language teaching and learning. I.M. Krsmanović, V. M. Petrović [4] point out four factors affecting quality language teaching, among them: teacher's skills and qualifications; teaching process; working conditions; evaluation and monitoring'.

Hong Thi Nguyen, W. Warren \& H. Fehring [8] identified such problems as: the teachers' teaching styles and methods; teachers' classroom management; teachers' investment for teaching; and students' abilities and attitudes.

We agree with S. Hubackova [10] who insists that 'the factors influencing success or failure may be various with each student'. This helps to conclude that particular students' groups have to be tested to later exploit the findings in designing foreign language lessons which could fit the needs on the quality teaching.

Researchers of the quality teaching are convinced that it is no longer possible to take into consideration only traditional factors, connected exclusively with the contents of study, school devices and teaching styles. The aspects like motivation, support at home, prior linguistic knowledge, student personality and even age are said to matter in a foreign language teaching and learning as well [11].

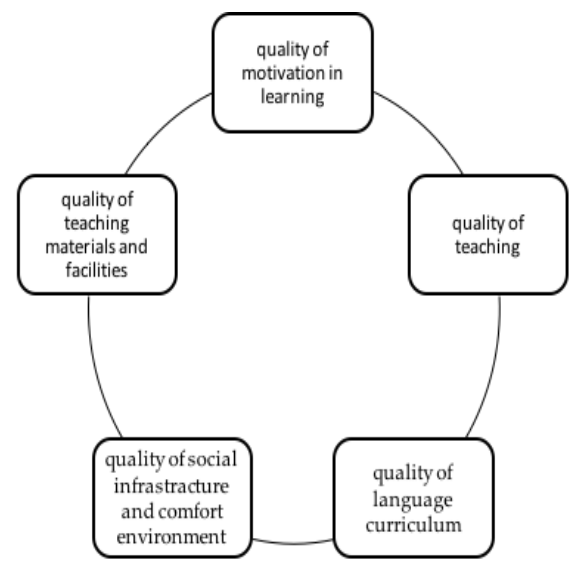

Fig. 1. Factors affecting quality of foreign language learning and teaching.

Literature review and personal pedagogical experience allowed to determine a group of factors which influence the process of foreign language acquisition, bringing it to the desired level of quality. (Fig 1.) 
Though, each factor is important by itself only a combination of interdependent and related aspects could help achieve a goal of foreign language teaching. For instance, students may assume that their motivational level is enough to guarantee high quality learning, however they might lose it in case there is no rapport in the classroom or if a teacher uses outdate information for discussion. Clearly, some factors from students' perspective would be given more importance than others but it is this what could provide us with the evidence what to pay attention to while working with particular groups.

Let us consider each factor in details. Motivation in learning. Motivation, according to Harmer [12] is an internal drive which pushes someone to do things in order to achieve something. Penny Ur [13] thinks that it is better to articulate this term from the point of view of ' a motivated student'. This is the one who is willing or even eager to invest effort in learning activities and to progress.

R.C. Gardner [14] provides 3 main characteristics of a motivated learner, he is the one who is (a) eager to learn the language, (b) willing to expend effort on the learning activity, and (c) willing to sustain the learning activity".

Motivation and success in education are interconnected. Success in a foreign language acquisition is linked to motivation in particular. As well as R.C. Gardner [14], Z. Dornyei [15], R. L. Oxford \& J. Shearin [16] we believe that attitude and motivation play a major role in a foreign language acquisition.

Foreign language is a subject that requires constant motivational level especially if is acquired in simulated, unreal conditions lacking the communication with native speakers. Motivation in second language is an eclectic, multifaceted construct, hence it needs to include different levels to integrate the various components [17]. If there is a real life application of a foreign language it would be learnt faster and more successfully. Students would have high level of motivation if they are encouraged a certain goal to achieve - to be able to travel, to find new friends, to be employed. Intrinsic motives can be fostered by 'theme-based curriculum' [11], by positive atmosphere in the classroom, by enthusiastic teacher and his/her teaching style and the way of communication with learners. Students could have de-motivating factors: 'lack of confidence in their English proficiency, crowded classes with unequal students' English levels' [8].

As motivation depends on quality teacher, here we turn to the second factor quality teaching, by which we mean teachers' skills and qualifications, teaching style and methods, approaches used as well as their personal characteristics.

The first and foremost aspect is teaching approach. We agree with M. Lochana \& G. Deb [18], J. C. Richards [9], G.M. Jacobs \& S. Hall [19] who consider the importance of student-centered collaborative approach, which in modern foreign language education paradigm is regarded to be the most effective. Following the definition of collaborative teaching and learning that is a 'variety of educational approaches involving joint intellectual effort by students, or students and teachers together' [20] we could point out its advantages over the traditional teacher-centered approach, as it:

- 'stands against the competitive system followed in a traditional classroom' [21];

- 'allows to obtain greater resources, recognition and reward when facing competition for finite resources' [22];

- treats 'teachers and students as equal partners, they can 'actively interact by sharing experiences and take on asymmetry roles' [23];

- helps teachers and students 'capitalize on one another's resources and skills (asking one another for information, evaluating one another's ideas, monitoring one another's work, etc.)' [24, 25];

- 'aims to provide learners with interactive tasks that can help them develop communicative competence [9]. 
The forms of interaction vary but all of them create atmosphere for productive foreign language communication. In a group work students work in small groups on tasks that entail interaction: conveying information, for example, or group decision-making, while a teacher walks around, listening, intervenes little if at all. In a question and answer form students answer teacher's questions, make their own questions to peers; a teacher is an expert and observer. When working individually, students work on tasks independently, and a teacher gives a task or a set of tasks, walks around monitoring and assisting where necessary. If we consider a collaboration form, students do the same sort of tasks as in 'individual work', but work together, usually in pairs; a teacher may or may not intervene (consulting). If a student happens to act as a teacher, students create tasks for quizzes and games, and the teacher consults on preparatory stage and participates in doing the tasks. In full-class interaction students debate a topic or do a language task as a class; a teacher may intervene occasionally to stimulate participation or to monitor [26].

Fulfilling the ideas of student-centered education teachers imply many roles. Ability to perform several tasks at ones appeals to English language teachers. They facilitate the process of learning, assist and navigate, provide guidance, solve disagreements. To provide high quality teaching teachers have to be engaged in constant development and take part in research. I. M. Krsmanović, V. M. Petrović [4] in their research distinguish six core components of teacher knowledge: a) practical knowledge: the teacher's repertoire of classroom techniques and strategies; b) content knowledge: the teacher's competence of grammar, phonology, second language acquisition, teaching theories; c) contextual knowledge: familiarity with the school context, norms, cultural and other relevant information; d) pedagogical knowledge: ability to restructure content knowledge for teaching purposes and to plan, adapt, improvise; e) personal knowledge: the teacher's personal beliefs and principles, and his/her individual approach to teaching; f) reflective knowledge: the teacher's capacity to reflect on and access his/ her own practice.

It is said that expert teacher could 'compensate for deficiencies in the curriculum or the resources' [4]. It is true if the teacher is experienced and enthusiastic enough, sooner or later it would be problematic to deliver high quality teaching if there is a lack of modern facilities and studying materials. Quality of teaching materials and facilities have a great impact on language learning and teaching, as well as, the quality of language curriculum on the basis of which materials are chosen [27]. Their findings prove that both students and teachers agree with an idea of an important role of facilities and quality textbooks play in efficient language education.

The choice of facilities and teaching materials is determined by the curriculum. The main aim of a quality curriculum is to enable students to acquire and develop the knowledge, skills and values, and the associated capabilities and competencies, to lead meaningful and productive lives'. The curriculum is considered to be successful if the students demonstrate stable progresses and implement that knowledge for their 'personal, social, physical, cognitive, moral, psychological and emotional development' [28]. English language curriculum should opt for relevance, be up-to-date, provide solid knowledge of the studied subject, guarantee flexibility and set clear aims.

High quality teaching and learning cannot be delivered without satisfactory education infrastructure. Overcrowded classes with old, sometimes broken furniture, absence of modern devices as computers, overhead projectors, white boards and labs hinder efficient and productive studying. Otherwise, comfortable studying conditions could enhance students' progress and increase motivation. That why, when we speak about language education we refer to infrastructure, which together with highly qualified teaching staff, effective teaching materials and facilities ensure quality foreign language acquisition. 


\section{Methods}

To obtain both qualitative and quantitative data the following collection methods were used: theoretical (analysis, generalization); diagnostic (questionnaire, interview), empirical (students observation); methods of statistics and graphic results.

The survey was conducted during the period from 2015 to 2017 at the Department of Foreign Languages in Economics, Business and Finance of the Institute of Management, Economics and Finance of the KFU. 67 first and second-year students of the same focus group of different cognitive abilities, score results, language proficiency and both genders were involved as the participants in this research. Participants' responses were confident and for research purpose only.

The focus group was interviewed twice: at the beginning of the first-year course and at the end of the second-year one. The aim of the survey was to find out what factors affect the quality of foreign language learning and teaching from students' perspective. The questionnaire comprised 3 types of questions specifically suited to the aim of the research: rank order scaling question requiring the students to rank the given factors according to their importance, closed question which supposed students to circle 'yes' or 'no' answer, open-ended question involving respondents' own answers. Q1 was designed to find out to what extent each factor has importance for the students. Q2 was aimed to define if students are satisfied or not with the quality of foreign language learning and teaching (for 2'd year students only). Q3 was devoted to clarify what influences the quality of foreign language learning and teaching from students' perspective.

\section{Findings}

The results obtained from the responses on the questionnaire (Q1) conducted among the first-year students revealed that the respondents ranked the factors from the most to the least essential (from 1 to 5) as follows:

1.quality of teaching

2. quality of teaching materials and facilities

3. quality of motivation in learning

4. quality of language curriculum

5. quality of social infrastructure and comfort environment (Fig.2).

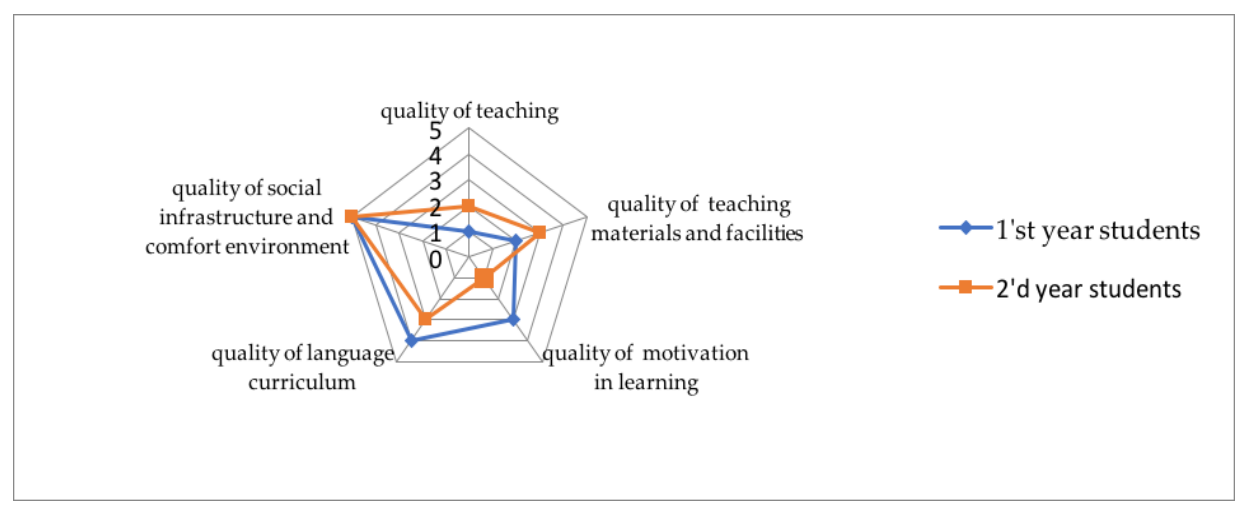

Fig. 2. Rank order of factors.

The factor "quality of teaching" was prioritized by almost a half of students (48\%) while no one ranked "quality of social infrastructure and comfort environment" as the most important by ranging it as number 4 or 5 . The "quality of teaching materials and facilities" 
received mostly ranks 2, 3 and 1, "quality of motivation in learning" -2 and 3 though $4.5 \%$ of respondents found this factor as dominating; "quality of language curriculum" was ranked 3,4 and 5 .

After the two years of study the ranking of factors showed the next scale:

1. quality of motivation in learning

2. quality of teaching

3. quality of teaching materials and facilities

4. quality of language curriculum

5.quality of social infrastructure and comfort environment (Fig.2)

The 2'd year students pleaded the "quality of motivation in learning" factors determining. The "quality of teaching" was prioritized by $28 \%$ and gathered the ranks from 1 to 3. Meanwhile the "quality of teaching materials and facilities" and "quality of language curriculum" scored the equal ranks of 3 and 4 . The factor "social infrastructure and comfort environment" has not changed its rank 5.

The answers to the Q2 demonstrated that the students were mostly satisfied with quality of the language learning and teaching: $73 \%$ responded positively, 22\% responded negatively, $4.5 \%$ didn't indicate their attitude.

The responses to the Q3 gave evidence that students mostly admitted that time management, appealing to the future profession; contemporaneity of language curriculum affected their quality of learning. Some pointed out personal attitude of a teacher toward them, and the system of monitoring and progress-checking as influential aspects.

\section{Discussion}

The comparative analysis showed that students recentralized the learning from teacher instructing to personal acquisition of language. To shape the students' willingness to study it was necessary to develop motivation stimulating the full realization of cognitive potential; to form the skills and abilities of effective learning; to target at the sustainable achieving of the results; to enhance students' confidence. The constant aspiration of students to improve their language competence was developed by student-centered approach; the creation of achievable perspectives in mastering foreign language; stimulating initiative, activity and perseverance; formation of "competitive personality" environment.

It was noted that increase in skills and competence took place when individual work was organized and effective methodological assistance to the student was provided; the hours for self-education were increased; interactive forms and techniques of teaching were implemented; individual creative assignments and the active involvement of students in research and development were carried out. Thus role of teacher shifted from the leading to assisting but was still vital.

Moreover, the quality of teaching encouraged personal motivation of students and their level of knowledge. Personal interest of teachers in obtaining a high result of their students defined the quality of motivation in learning. The most successful approach is to organize and implement the search process, to initiate the class activity, to motivate and aim students at revealing their potential for competitiveness.

The fact that factors 'quality of teaching materials and facilities' and 'quality of language curriculum' were reconsidered to be equally important constitutes that means of transmitting information and applicability of knowledge are vital for contemporary students. Furthermore, the quality is measured not in numbers, but by the timeliness and suitability for the learning of modern specialists. These will allow not only to diversify the learning process of ESP but significantly improve foreign language acquisition. 
However, the factor 'quality of social infrastructure and comfort environment' reached the least popularity among young generation which demonstrates that decorations of premises, number of students in one class, existence of advanced equipment was not found to be a priority when discussing the issue of quality education.

The created atmosphere of cooperation and collaboration, proper teaching process, updated methods and materials developed prospects for the success of each student and facilitated their confidence, which made the majority of students be satisfied with the quality of learning and teaching.

\section{Conclusion}

Research carried out and the results gained allowed the authors to conclude that students recognize quality education, have their own understanding of this phenomena and factors affecting it. A combination of 5 quality factors could provide students with adequate learning environment to acquire communicative competence. The acknowledgment of student's opinions is substantial for optimization and facilitating educational process in order to form qualified human resources. The results received give optimistic forecasts regarding the improvement of the quality education.

\section{References}

1. E.V. Grigoryeva \& I.M Solodkova, Foreign language skill as a component of selfdevelopment procedure: undergraduate and graduate levels. Social Sciences and Interdisciplinary Behavior - Proceedings, 99, (2016)

2. A. Pulverness., I.I. Klimova, O.A. Kalugina, D.G. Vasbieva, L.R. Ismagilova, The formation of students' intercultural communicative competence in an English language learning environment at a non-linguistic higher school. XLinguae, 10, (4), 381, (2017)

3. S.V. Kolyadko, Problems of selecting a productive lexical minimum for teaching foreign language communication in a non-linguistic university. Linguistic education in the university: A methodical manual for teachers of higher education, postgraduate students, students.- SPb .: KARO, 4, 113, (2005)

4. I.M. Krsmanović \& V.M. Petrović, Factors affecting quality in teaching English (as a second language). 6th Research/Expert Conference with International Participations "Quality 2009“, Neum, B\&H, 702, (2009)

5. N. Galskova, Modern Methods of Foreign Languages: A Handbook for Teachers. 2nd ed., Moscow: ARCTI, 15, (2003)

6. L.A. Liu, New Perspective on the Goals of TEFL in China. Internet TESL J., IX, (11), (2003)

7. W.A. Rivers, A practical guide to the teaching of English as a second or foreign language. New York: Oxford University Press, (1978)

8. H.T. Nguyen, W. Warren \& H. Fehring, Factors Affecting English Language Teaching and Learning in Higher Education. Engl. Lang. Teach., 7, (8), 97, (2014)

9. J.C. Richards, Approaches and methods in language teaching (2nd ed.). Cambridge, U.K., (2001)

10. S. Hubackova, Factors influencing the quality of teaching and the foreign language knowledge. 7th World Conference on Educational Sciences, (WCES-2015), Novotel Athens Convention Center, Athens, Greece. Procedia - PROCD SOC BEHV, 197, 1952, (2015) 
11. A. Miller, 9 factors that influence language learning. Retrieved from https://www.whitbyschool.org/passionforlearning/9-factors-that-influence-languagelearning,( n.d.)

12. J. Harmer, The Practice of English Language Teaching // Essex: Longman Press, 51, (2001)

13. Penny Ur, A course in Language Teaching. Practice and Theory, Cambridge University Press, (1996)

14. R.C. Gardner, Social psychology and second language learning: The role of attitudes and motivation. London: Edward Arnold, (1985)

15. Z. Dornyei, Motivation in second and foreign language learning. ET: Int. Ab. J. for Lang. Teach., 31, (3), 117, (1990)

16. R. Oxford \& J. Shearin, Language Learning Motivation: Expanding the Theoretical Framework. Mod. Lang. J., 78, 12, (1994)

17. Z. Dornyei, Motivation and motivating in the language foreign language classroom. Mod. Lang. J., 78, (3), 273, (1994)

18. M. Lochana \& G. Deb, Task-based teaching: Learning English without tears. Asian EFL J., 8, (3), 140, (2006)

19. G.M. Jacobs \& S. Hall, Implementing cooperative learning. In J. C. Richards, \& A. W. Renandya (Eds.), Methodology in language teaching: An anthology of current practice. New York: Cambridge University Press, 52, (2002)

20. B.L. Smith \& J.T. MacGregor, "What is Collaborative Learning?" in Goodsell, Maher, Tinto, Smith \& MacGregor's. Collaborative Learning: A Sourcebook for Higher Education; National Center on Postsecondary Teaching, Learning and Assessment; Pennsylvania State University, (1992)

21. Dr. K. B. Ranee, edited by: N. Gunnell A Definition of Collaborative Learning. Retrieved from http://www.brighthubeducation.com/teaching-methods-tips/69801definition-of-collaborative-learning/, (2012)

22. C.S. Wagner, \& L. Leydesdorff, Globalisation in the network of science in 2005: The diffusion of international collaboration and the formation of a core group, (2005)

23. R. Mitnik, M. Recabarren, M. Nussbaum, \& A. Soto, Collaborative Robotic Instruction: A Graph Teaching Experience. Comp. \& Ed., 53, (2), 330, (2009)

24. M.M. Chiu, Group problem solving processes: Social interactions and individual actions. Theory Soc. Behv., 30, (1), 600, (2000)

25. M.M. Chiu, Flowing toward correct contributions during groups' mathematics problem solving: A statistical discourse analysis. J. Learn. Sci., 17, (3), 415, (2008)

26. E.O. Zalyaeva, I.M. Solodkova, Teacher-student collaboration: Institute of economics and finance Kazan federal university approach. Procedia - PROCD SOC BEHV, 152, 1039, (2014)

27. T.T. Abebe, \& L.M. Davidson, Assessing the role of visual teaching materials in teaching English vocabulary (Report). Lang. In India, 12, (3), 524, (2012)

28. P. Stabback, What Makes a Quality Curriculum? Current and Critical Issues in Curriculum and Learning, 2, IBE/2016/WP/CD/02, (2016) 